\title{
Is Unish Moving toward Becoming a More Analytic Language?: With Special Reference to Morphological Changes
}

\author{
Jin-young Tak \\ Sejong University, Korea
}

\begin{abstract}
This paper scrutinizes the morphology of Unish, one of the international auxiliary languages, with respect to its correlations of word order typology and discusses a linguistic type of Unish. It has been reported that Unish has the fixed word order SVO (i.e., subject-verbobject), little inflection, which means there are no cases of nominal
\end{abstract}

\footnotetext{
$\S$ I would like to thank anonymous reviewers who helped me develop this paper further. All the errors are the author's responsibility.
}

Jin-young Tak

Professor, Department of English Language \& Literature, Sejong University, Korea

Email: jytak@sejong.ac.kr

Received 10 August, 2020; Revised 1 September, 2020; Accepted 15 September, 2020

Copyright (C) 2020 Language Research Institute, Sejong University Journal of Universal Language is an Open Access Journal. All articles are distributed online under the terms of the Creative Commons Attribution Non-Commercial License (http://creativecommons.org/licenses/by-nc/3.0) which permits unrestricted non-commercial use, distribution, and reproduction in any medium, provided the original work is properly cited. 
148 Is Unish Moving toward Becoming a More Analytic Language?

or accusative markers, and no gender distinction markers. In light of this, this paper proposes that Unish is an analytic language where the syntactic or the semantic information is mostly conveyed by relying on the word order rather than the morphological processes. Finally, it is shown in this paper that Unish has evolved, and it is heading towards a stricter analytic language via the elimination of inflection and the reconstruction of the pronoun systems. These morphological changes that Unish has undergone are in accordance with linguistic typology.

Keywords: linguistic typology, analytic, synthetic, morphological change, universal, word order

\section{Introduction}

This paper addresses the correlational phenomena between morphology, which includes inflection, and syntax, which includes the basic word order, of Unish from the perspective of linguistic typology, which adopts the argument that there is a correlation between the word order and the morphological case (Haspelmath 2000). It is then proposed that Unish has evolved to become more analytic by discarding inflection and modifying its pronoun system. Unish, an international auxiliary language coined from Universal Language or Universal English, has been developed by Sejong University in Korea since 1995. Approximately 14,000 words so far have been constructed through careful vocabulary selection processes from 14 natural languages, including Arabic, Chinese, English, French, German, Greek, Hindi, Italian, Japanese, Korean, Latin, Portuguese, Russian and Spanish, and one artificial language, including Esperanto. ${ }^{1}$ Furthermore, geared to the basic principles, such as simplicity, logicality, and regularity the

\footnotetext{
${ }^{1}$ Refer to $<$ https://en.wikipedia.org/wiki/Unish>.
} 
research team at Sejong University has built the grammar of Unish and is continuously reshaping it, which is pertinent to linguistic universality (Lee 2002, Moskovsky \& Libert 2004, Libert 2011).

For centuries, the international auxiliary languages, which are broadly called artificial languages, planned languages, or constructed languages, have been consciously invented mainly in order to provide a more efficient vehicle for international communication (Libert 2003, 2011, 2018; Libert \& Moskovsky 2011). However, they have hardly been of interest in the field of linguistics, which is indicated by Okrent (2014), since they are regarded as peripheral languages with the lack of historical derivation, speech communities, and native speakers who can motivate language evolution. Moreover, most research on international auxiliary languages provides very little, if any, information on what language type (i.e., an analytic or a synthetic language) they belong to, based on cross-linguistic investigation and what morphological or syntactic properties they are to have. Therefore, it is worthy to examine this topic while bringing up one of international auxiliary languages, Unish.

This paper is organized as follows: Section 2 presents the preliminary remarks on the language types and the linguistic universals relevant to the word order and the morphological processes. Section 3 posits that Unish has become a stricter analytic language by discarding some inflectional morphemes by considering its fundamental word-formation rules and word order. The current proposal then accounts for the constraints that are incorporated with the cross-linguistic tendencies. Finally, Section 4 offers the conclusion and a summary of this research. 


\section{Preliminary}

\subsection{Word Order Typology}

Since Greenberg (1963) who investigated a set of 30 languages, a great amount of research about linguistic typology has been conducted (Greenberg 1966a, 1966b; Hawkins 1983; Mithun 1987; Croft 1991, 2003; Givón 1997, 2001). Linguistic typology is a branch of linguistics that attempts to categorize languages based on the similarities and the differences in the structure by means of the phonological inventories, the word-formations, the grammatical constructions, and the word order. In this research, word order typology and morphology of Unish were probed into. Along with this observation, it is asserted that Unish was originally rather analytic and is gradually moving to a stricter analytic language.

The concept of word order is significant in the field of linguistic typology, since it is presumed that word order is tightly correlated to other distributional universals even though it is still arguable how many word order formulations exist.

Greenberg (1963), Keenan (1978), Comrie (1981, 1989), Derbyshire \& Pullum (1981, 1986), and Payne (1990) suggested the following six word order types: SOV, SVO, VSO, VOS, OVS, and OSV. Lehmann (1973, 1978), Vennemann (1974, 1976), and Dryer (1991, 1992, 1997) collapsed these six types into two types, OV and OV. ${ }^{2}$ Dryer (1991, 1992, 1997) proposed the two-way OV-VO distinction based on the examination that the word order characteristics of SVO languages differ little from those of VSO or VOS, and this also applies to the relations between the SOV languages and the OVS languages

${ }^{2}$ Here, "S" stands for "subject", "V" for "verb", and "O" for "object." 
or the OSV languages.

Despite Dryer's and other typologists' proposal, this paper relies on Greenberg's six-way word order typology, which is much more widely accepted. Following Greenberg (1963), Tomlin (1986) classified a sample of 402 languages by investigating the six word order types and asserted that the vast majority fall in two categories, which include SVO and SOV. This is illustrated in Table $1 .^{3}$

Table 1. Word Order Distribution (Tomlin 1986)

\begin{tabular}{|c|c|c|}
\hline Word Order Type & $\%$ & Language \\
\hline SVO & 41.79 & English, Chinese \\
\hline SOV & 44.78 & Korean, Turkish \\
\hline VSO & 9.20 & Welsh \\
\hline VOS & 2.99 & Malagasy \\
\hline OVS & 1.24 & Hixkaryana \\
\hline OSV & 0 & Warao \\
\hline
\end{tabular}

Given the fact that the difference between the SVO and the SOV percentages and between the VOS and the OVS percentages is not statistically significant, Tomlin (1986) proposed the following relative frequency:

(1) $\mathrm{SVO}=\mathrm{SOV}>\mathrm{VSO}>\mathrm{VOS}=\mathrm{OVS}>\mathrm{OSV}$

3 Table 1 is extracted from http://www.applet-magic.com/wordordertyp.htm. In Table 1, Malagasy, an Austronesian language, is an official language in Madagacar, and Hixkaryana is a language in Amazonia spoken by Carib tribal group. Warao is spoken in Venezuela. 
152 Is Unish Moving toward Becoming a More Analytic Language?

Word order typology, the subfield of linguistics that studies how the syntactic constituents of a language are ordered and how different languages operate different orders, is correlated with diverse syntactic domains, such as adjectives, genitives, and noun phrases. It is well documented that languages, which use a relatively fixed word order, often depend on the order of constituents to convey grammatical information (Krifka 1985, Fedzechkina et al. 2017). More specifically, many languages with a fixed word order tend to use less cases and agreement markers or use another type of marker (Krifka 1985). In contrast, languages that employ a flexible word order convey grammatical information via inflection even though they have a preferred word order. In other words, a fixed word order is used to decrease the processing of sentence semantics and reduce ambiguity.

Reducing ambiguity is one of tasks in language communication. One vehicle to make a speech less ambiguous is to employ a rigid order and another is to utilize inflection by labeling the constituents with case, agreement, or other markers (Krifka 1985, Blake 1994, Amberber \& de Hoop 2005, Butt 2006). These two methods are implemented differently. A fixed word order reduces expressiveness, while inflection increases the load to the speakers. Therefore, it is reported that a fixed word order and strict inflection hardly co-occur. ${ }^{4}$ Therefore, Haider (1988) proposed that languages that are characterized by a lack of morphology represent a rigid word order and vice versa.

This argument is further supported by the history of English. Old English had mostly an SOV word order between 1000 A.D. and 1150 A.D., but around 1200 A.D., it had become mostly an SVO word order (PPCME2 Corpus, Kroch \& Taylor 2000). In other words, Old English word order was freer than Modern English, and it looked like German does today. The case system that English had at the time

${ }^{4}$ Refer to $<$ https://en.wikipedia.org/wiki/Word_order $>$. 
conveyed the grammatical relations. English then lost most of the inflectional morphemes, and the word order became fixed and then more significant, which expresses the grammatical information configurationally not morphologically.

\subsection{Analytic or Synthetic}

It is asserted that the grammatical construction can similarly be analytic if it uses separate words or a strict word order. Hence, in light of language typology, an analytic language, which is defined as a language that primarily conveys relationships between words in sentences with a low morpheme-per-word ratio, tends to statistically have a fixed word order.

For example, Mandarin Chinese, one of analytic languages, has few inflectional morphemes attached to nouns. Therefore, 三天 sān tiān, which means three days, is realized without a plural marker; its literal meaning is three day, compared to 一天 yī tiān, which is one day. ${ }^{5}$ In this language, most words are composed of one-syllable or twosyllable morphemes, which is an independent word, despite the existence of some exceptional synthetic compound words. Additionally, the word order in Mandarin Chinese is very rigid.

English, which is another analytic language, has the fixed word order SOV. For example, the English expression The boy chases the dog conveys the fact that the boy is acting on the dog analytically via word order. In the same sense, The dog chases the boy delivers a different meaning from the former sentence. However, English is not that as analytic as Mandarin Chinese. Different from Mandarin Chinese, English does use inflection morphemes for numbers, such as one dog and three dogs, and for possession, such as the boy's ball and

\footnotetext{
${ }^{5}$ Refer to $<$ https://en.wikipedia.org/wiki/Analytic_language $>$.
} 
154 Is Unish Moving toward Becoming a More Analytic Language?

the dogs' bone, which are synthetic language properties. Even though English is weakly inflected, English is still classified as an analytic language, since it is comparatively more analytic than other IndoEuropean languages. In fact, most of the analytic languages are not purely analytic, but many of them rely primarily on analytic syntax. Many analytic languages use syntax to covey information that is encoded rather than inflection in the synthetic languages. Therefore, morphology in analytic languages is not significantly important, but syntax is critically important. Also, word order in synthetic languages is not significant, but morphology is highly significant.

Given the above observations, it is generally accepted that there is no absolute analytic language. Whether a language is analytic or synthetic is, therefore, a matter of degree.

In contrast, synthetic languages, such as Korean, Turkish and Latin allow affixation in such a way that words may include two or more morphemes. In addition, they are characterized as having a fairly flexible word order due to a full range of inflectional morphemes, which identify the grammatical functions.

Haspelmath \& Michaelis (2017) suggested that analyticity is diachronically increasing in a number of European languages, such as German. German is an inflected language with four cases (e.g., nominative, accusative, genitive, dative), three genders (e.g., masculine, feminine, neutral), and two numbers (e.g., singular, plural). This permits German to have a more flexible word order than English. Even though German has a basic SOV word order, the inflectional morphemes allow more leniency on the word order. Therefore, even though changing the word order of an English sentence entails a different meaning of the sentence, German preserves the meaning of a sentence even after changing the order of constituents in the sentence. However, according to Haspelmath \& Michaelis (2017), the 
development of the prepositional phrases for genitive cases in German sheds light on the movement from the syntactic to the analytic. The examples by Haspelmath \& Michaelis (2017) are shown below ${ }^{6}$ :

a. des $\quad$ haus-es
GEN-the house-GEN
'the house's'
b. von dem haus
of DAT-the house
'of the house' 7

The example in (2a) makes use of the inflectional morpheme attached to the noun in order to denote the genitive, but the second phrase uses the preposition von. This may support the assumption that German utilizes an analytic property (Haspelmath \& Michaelis 2017).

Furthermore, several recent studies showed that analytic grammatical structures are easier for foreign language learners even though the correlations between morphological complexity and other social environments should be considered (Lupyan et al. 2010). The evolution of creole, whose grammar become much simpler over the course diachronically, is also evidence of this argument.

6 The following abbreviations are used in the gloss: ACC (accusative), DAT (dative), GEN (genitive), NOM (nominal), POSS (possessive), PL (plural), PST (past), SG (singular).

7 Refer to $<$ https://en.wikipedia.org/wiki/Synthetic_language>. 
156 Is Unish Moving toward Becoming a More Analytic Language?

\section{Analysis}

\subsection{Unish as an Analytic Language}

The research team of Unish, an international auxiliary language, has been developing its grammar and vocabulary since its inauguration. Along with this line, the current paper investigates the two broad developmental phases of Unish and discusses the linguistic properties of Unish in order to prove that Unish is systematically and continuously moving towards becoming a stricter analytic language.

First, it is proposed that a word order type of Unish supports that it is more likely to be classified as an analytic language. Unish has a very rigid word order SVO, which includes a subject being followed by a verb and an object in this sequence. Therefore, cases of noun phrases, especially, nominal, accusative, and dative, are assigned mainly based on their location rather than utilizing the inflectional morphemes. Among Greenberg's (1963) 45 universals, it is proposed that Unish obeys following linguistic universals 1 and 8.

(3) a. Linguistic Universal Number $1^{8}$

In declarative sentences with nominal a subject and an object, the dominant order is almost always one in which the subject precedes the object.

b. Linguistic Universal Number 8

When a yes-no question is differentiated from the corresponding assertion by an intonational pattern, the distinctive intonational features of each of these patterns are reckoned from the end of the sentence rather than from the beginning of the sentence.

\footnotetext{
${ }^{8}$ Refer to $<$ https://en.wikipedia.org/wiki/Greenberg\%27s_linguistic_universals $>$.
} 
Supporting the argument above, consider the following Unish data from Lee (2002) and Sejong Language Institute (2012, 2020).
a. Declarative Sentence
Tim lov beisbol game.
Tim love baseball game
"Tim loves a baseball game."
b. Yes-No Interrogative Sentence
Tim lov beisbol game?
Tim love baseball game
"Does Tim love a baseball game?"
c. Wh-Question Sentence
Tim lov who?
Tim love who
"Whom does Tim love?"

The data in (4) clearly show that word order is rigidly fixed in Unish even in an interrogative sentence. In accordance with Greenberg's linguistic universal 8, a word order in Unish remains intact even in interrogative sentences, which means that the subject and the verb are not inverted to form interrogative sentences as in English and many other European languages. Also, the rising intonation and a question mark at the end of sentences are a signal of interrogative sentences.

However, English behaves differently with the formation of interrogative sentences, which entails the inversion of the subject and the verb. For this reason, Greenberg's linguistic universal 11 is active in English, but it is dormant in Unish. 
158 Is Unish Moving toward Becoming a More Analytic Language?

(5) Linguistic Universal Number $11^{9}$

Inversion of the statement order so that a verb precedes the subject occurs only in languages where the question word or the phrase is normally initial. This same inversion occurs in yes-no questions only if it also occurs in interrogative word questions.

Greenberg's universal 1, 8 and 11 demonstrate that Unish is more analytic than English, since there is no inversion for an interrogative sentence.

Second, a further examination of the pronoun systems of Unish in comparison with Esperanto supports that Unish has evolved toward being more analytical. The tables below illustrate these assumptions.

Table 2. The Earlier Stage: Pronoun System in Unish

\begin{tabular}{|c|c|c|c|c|c|c|}
\hline & \multicolumn{2}{|c|}{ NOM } & \multicolumn{2}{c|}{ ACC } & \multicolumn{2}{c|}{ GEN } \\
\hline & SG & PL & SG & PL & SG & PL \\
\hline First-person & me & mes & me & mes & me's & mes's \\
\hline Second-person & de & des & de & des & de's & des's \\
\hline Third-person & le & les & le & les & le's & les's \\
\hline
\end{tabular}

${ }^{9}$ Refer to $<$ https://en.wikipedia.org/wiki/Greenberg\%27s_linguistic_universals>. 
Table 3. The Later Stage: Pronoun System in Unish

\begin{tabular}{|c|c|c|c|c|c|c|}
\hline & \multicolumn{2}{|c|}{ NOM } & \multicolumn{2}{|c|}{$\mathrm{ACC}$} & \multicolumn{2}{|c|}{ GEN } \\
\hline & SG & PL & SG & PL & SG & PL \\
\hline First-person & $\mathrm{i}$ & we & $\mathrm{i}$ & we & i’s & we's \\
\hline Second-person & $\mathrm{u}$ & ue & $\mathrm{u}$ & ue & u's & ue's \\
\hline \multirow{3}{*}{ Third-person } & he & \multirow{3}{*}{ dey } & he & \multirow{3}{*}{ dey } & he's & \multirow{3}{*}{ dey's } \\
\hline & she & & she & & she's & \\
\hline & it & & it & & it's & \\
\hline
\end{tabular}

Table 4. Pronoun System in Esperanto (Lee 2002)

\begin{tabular}{|c|c|c|c|c|c|c|}
\hline & \multicolumn{2}{|c|}{ NOM } & \multicolumn{2}{|c|}{ ACC } & \multicolumn{2}{|c|}{ GEN } \\
\hline & SG & PL & SG & PL & SG & PL \\
\hline First-person & $\mathrm{mi}$ & ni & $\min$ & $\operatorname{nin}$ & mia & nia \\
\hline Second-person & vi & vi & vin & vin & via & via \\
\hline \multirow{3}{*}{ Third-person } & li & \multirow{3}{*}{ ili } & $\operatorname{lin}$ & \multirow{3}{*}{ ilin } & lia & \multirow{3}{*}{ ilia } \\
\hline & $\hat{\mathrm{s}} \mathrm{i}$ & & ŝin & & ŝia & \\
\hline & gi $\mathrm{i}$ & & gin & & ĝia & \\
\hline
\end{tabular}

As seen in Table 2 and Table 3, in the earlier developmental stage of Unish, it had a very simple pronoun system compared to English and Esperanto (Lee 2002, Libert 2011). Unlike English and Esperanto, there was no gender distinction and there was no case distinction between the nominal and the accusative forms even though the genitive case is realized by the affixation of morpheme "-s." Moreover, it was much easier to derive the plural pronouns in Unish, since they underwent a straightforward process, which involves the 
affixation of the plural morpheme "-s" to their corresponding singular pronouns.

In contrast to what is seen in the later version of Unish (Table 3), the plural pronouns are independent words, as opposed to words that are derived through the affixation of the plural marker "-s." This is in accordance with the features of an analytic language. In fact, proposing a monomorphemic independent word and not attaching the plural morpheme "-s" to the singular pronouns to derive the plural pronouns, increases analyticity.

As shown in Table 4, Esperanto utilizes the rigid synthetic features as follows: The personal pronouns take the morpheme "-n" for an accusative case and the morpheme "-a" for a genitive case.

Therefore, when the pronoun system is exclusively considered, it is proposed that Unish is moving towards a stricter analytic language. The earlier Unish was more synthetic, since the plural suffix took a crucial role in the derivation of the plural pronouns. However, in the later Unish, the plural pronouns are independent words.

Third, considering how passive sentences are formed in Unish, which is shown in (6), the earlier version of Unish had synthetic passive patterns (Lee 2002, Libert 2012). This means that in order to form passive sentences, Unish underwent an attachment of the passive prefix "-be" to a verb root, which is illustrated in (6b). The data are extracted from Lee (2002) and Libert $(2011,2012)$.
a. Me skrib-ed buk.
I write-PST book
"I wrote a book."

b. Buk be-skrib-ed be me.

book PASS-write-PST by I

"A book was written by me." 
As seen in (6), in the earlier Unish, to transform an active sentence to the corresponding passive one, a passive prefix "be-" is attached to the left of a verb, which is a syntactic pattern that utilizes the morphological processes. Many international auxiliary languages, such as Gilo, Lingua and Veltpartl, possess similar patterns as the earlier Unish, which facilitated an inflectional prefix "be-" (Moskovsky \& Libert 2004). This is called strict morphological passives by Keenan \& Dryer (2007) or synthetic passives by Moskovsky \& Libert (2004). There are two noticeable points that should be captured in the earlier Unish: i) There was only one inflectional prefix, which is used to derive passives, and ii) a preposition whose meaning is by also had a same surface form as an inflectional prefix "be-", which increases ambiguity.

However, the passive sentence in (7b) is realized with the independent word be, which can vouch for the analytic passives. Based on the fact that the analytic passive form be whose meaning is to be is used as an auxiliary verb, it may be supported that the later Unish marks analytic passives, which is noted by Moskovsky \& Libert (2004). This is illustrated in (7).
a. I lov-ed u.
I love-PST you
"I loved you."
b. U be-ed lov-ed by i.
You be-PST love-PASS by I
"You were loved by me."

As seen in (7), the inflectional prefix "be-" in the earlier stage disappeared in the Unish grammar. Instead, in the later development, Unish takes the auxiliary be before a main verb attached by the passive 
162 Is Unish Moving toward Becoming a More Analytic Language?

suffix "-ed." This results in a similar passive pattern to the English word "be ... Verb-ed" (Moskovsky \& Libert 2004). The use of the independent word "be" as an auxiliary is detected in many other natural languages, which include English, Latvian and Latin (Moskovsky \& Libert 2004). In comparison to the synthetic passives in the earlier Unish, Unish in the later stage is characterized as an analytic passive pattern. The evolution of analytic passive sentences in Unish sheds light on the arguments that Unish is moving to become a more analytic language.

Fourth, consider how plurality for nouns has developed in Unish. The plural form of all nouns, which include pronouns and common nouns but not proper nouns, was derived by attaching "-s" to their singular form in the earlier Unish. In order to retain regularity, irregular plural patterns of a noun are then not permissible in both the developmental stages in Unish. However, in the later stage, it is interesting to note that the plural formation rules are doomed to be readjusted due to the fact that the new pronoun system is proposed. The plural suffix “-s" does not mark plurality for the pronouns, since the plural pronouns, we, which is the $1^{\text {st }}$ person, $u e$, which is the $2^{\text {nd }}$ person, and dey, which is the $3^{\text {rd }}$ person, are newly coined. Moreover, it is not obligatory to attach the plural marker "-s" to derive plural nouns. This is illustrated in (8). The data are drawn from Unish Grammar (Sejong Language Institute 2012, 2020). 
(8) Plural Agreement in Unish
a. The Earlier Stage $\begin{array}{ll}\text { aquarium : aquarium-s } & \text { kakto : kakto-s } \\ \text { aquarium : aquarium-PL } & \text { cactus : cactus-PL }\end{array}$
b. The Later Stage

I buy-ed du banana-s.
I buy-PST
or two banana-PL
I buy-ed du banana.
I buy-PST two banana
"I bought two bananas."

As shown in (8b), Unish in the later stage is characterized by the optionality of the plural suffix in the process of the plural noun derivations.

Both $d u$ bananas and du banana are permissible. In contrast, the data in (8a) illustrates that the nouns in the earlier Unish had to agree with the number without fail. This proves that Unish has evolved into being more analytic by giving options to the language users, because they can use a plural marking system that is less strict. Of course, some cases, such as I buyed banana evoke ambiguity, since I buyed banana can be interpreted into either I bought one banana or I bought two or more bananas. Even though this example increases ambiguity, which considers the finding by Krifka (1985), many languages with the fixed word order have a tendency to use less cases and agreement markers. This optionality of the plural suffix in Unish may be seen as a movement to a more analytic language.

The evidence that exists thus far to support the evolution of Unish toward a stricter language has been presented. In the next subsection, this development is accounted for in terms of the universal constraints. 
164 Is Unish Moving toward Becoming a More Analytic Language?

\subsection{Unish with the Framework of Universality}

In natural languages, morphological changes are driven by opacity attributable to various domains, such as phonology, syntax, and sometimes morphology by itself (Anderson 1980, 1988). Various sources, such as Goddard (1967), Thompson \& Thompson (1969), Andersen (1973), Anderson (1988), Lightfoot (2002), and Campbell (2004) make this quite clear. Therefore, to resolve this type of opacity, the grammar of different languages seem to find a balance between two communicative pressures in order to be simple enough to allow the speaker to easily produce sentences, but they also need to be simultaneously complex enough to be unambiguous for the hearer (Müller 1999a, 1999b; Lightfoot 2002). Keeping the balance then pushes a language to undergo morphological changes. Like natural languages, Unish has also been developing through morphological changes in a similar way.

Based on Han et al. (2020), this paper proposes four constraints to elucidate the morphological changes in Unish, which motivate the development towards a more analytic language: HARMONY, STAY, EXPLICITNESS and ECONOMY.

(9) Constraints (Krifka 1985; Müller 1999a, 1999b; Moskovsky \& Libert 2004)

a. EXPLICITNESS: The grammar should be unambiguous.

b. ECONOMY: The grammar is simple enough to have a language used with less efforts.

c. STAY: The structure movement is not allowed. ${ }^{10}$

d. HARMONY: All the heads are initial, or all the heads are final. ${ }^{11}$

10 The constraint Stay by Müller (1991a) is modified in this paper.

11 Refer to an online teaching material by Manfred Krifka $<$ http://www.sfs.unitue 
The constraint ECONOMY assures that the grammar of a language is simple, while EXPLICITNESS is complex enough to be unambiguous (Müller 1999a, 1999b; Lightfoot 2002). Then, these types of balances explain the correlations between the word-order generalizations and the morphological changes across the languages (Hahn et al. 2020). Moreover, the constraint STAY prohibits the overt movements, which results in a very rigid or a fixed word order. Furthermore, the constraint HARMONY, which obeys Greenberg's linguistic universals, may guarantee the hypothesis of the head directionality, which ensures the uniform location of the head of the constituents in a language.

This research proposes that the constraint STAY is the most highly ranked constraint throughout all the developmental processes in Unish, since there is no inversion of a subject and a verb in interrogative sentences in Unish. In contrast, the constraint HARMONY is violable and lower ranked due to the fact that Unish should not need to obey Greenberg's linguistic universal 36, which may vouch for the head directionality for the genitive form.

(10) Linguistic Universal Number $36^{12}$

In languages with prepositions, the genitive almost always follows the governing noun, while in languages with postpositions it almost always precedes.

According to Greenberg's linguistic universal 36, if a language has an SVO order that is head-initial, the language mostly has prepositions rather than postpositions. Since the head of a prepositional phrase is a preposition, it almost always occurs initially at the beginning of the prepositional phrase. From this point of view, a genitive form should

bingen.de/ tuebingen.de/ gjaeger/lehre/ws0910/languagesOfTheWorld/word OrderTypology.pdf $>$.

12 Refer to $<$ https://en.wikipedia.org/wiki/Greenberg\%27s_linguistic_universals $>$. 
be preceded by a noun since a noun is a head of noun phrases. In order to cope with this directionality, English and German make use of prepositional phrases for genitive case, such as a book of a boy along with a boy's book. Like English and German, Unish also permits both patterns, which supports that HARMONY is not a decisive constraint and is, therefore, ranked low in a constraint hierarchy. In other words, the violation of this constraint is not critical since it does not affect to derive an optimal output.

Given the constraints in (9), for the earlier stage of Unish with more inflection, this paper proposes that the constraint Explicitness is ranked above ECONOMY (EXPLICITNESS $>>$ ECONOMY), but for the later stage these two constraints are switched (ECONOMY $>>$ EXPLICITNESS). That is, a need to reduce ambiguity for the listeners, favoring the constraint EXPLICITNESS, is more focused in the earlier Unish. However, in the later Unish, simplicity for the speakers is more highlighted, resulting in the promotion of the constraint ECONOMY. Again, the location of a subject, a verb, and an object is fixed; the constraint STAY is not undominated. This is formulated as in (11).

(11) Constraint Ranking

a. The Earlier Stage of Unish STAY $>$ EXPLICITNESS $>>$ ECONOMY, HARMONY

b. The Later Stage of Unish STAY $>$ ECONOMY >> EXPLICITNESS, HARMONY

In this section, a result from the process of optimization was investigated for the efficient communication among humans, and it trades off the need to increase explicitness with the need to improve economy, which entails the morphological changes in Unish. Moreover, Unish is systematically moving to obtaining more analytic features. 


\section{Conclusion}

This paper is based on the assumption that there are correlations between word order typology and morphological processes in languages. Based on the investigations of the word order and some diachronic changes of the word-formation rules in Unish, it is then proved that Unish was originally an analytic language, which syntactic or semantic information is mostly carried out via word order rather than inflection. Additionally, the current study sheds light on the development of Unish, which argues that Unish is becoming a stricter analytic language through the attenuating functions of the inflectional morphemes and reconstructing the pronoun systems. Finally, this paper briefly argues that the morphological changes that Unish has gone through are in accordance with linguistic typology.

This paper also makes explicit predictions about languages that favor the correlation between the constituent order flexibility and the presence of inflection. Therefore, this research is expected to provide an insight for language designers not to overlook linguistic typology when they construct an international auxiliary language.

\section{References}

Amberber, M. \& H. de Hoop (eds.) 2005. Competition and Variation in Natural Languages: The Case for Case. Oxford: OUP.

Andersen, H. 1973. Abductive and Deductive Change. Language 49, 567-595.

Anderson, S. 1980. On the Development of Morphology from Syntax. In J. Fisiak (ed.), Historical Morphology 51-69. The Hague: Mouton and Company. 
168 Is Unish Moving toward Becoming a More Analytic Language?

Anderson, S. 1988. Morphological Change. In F. Newmeyer (ed.), Linguistics: The Cambridge Survey I 324-362. Cambridge: CUP. Blake, B. 1994. Case (Cambridge Textbook in Linguistics). Cambridge: CUP.

Butt, M. 2006. Theories of Case (Cambridge Textbooks in Linguistics). Cambridge: CUP.

Campbell, L. 2004. Historical Linguistics: An Introduction. 2nd edition. Cambridge, MA: MIT Press.

Comrie, B. 1981. Language Universals and Linguistic Typology. Chicago, IL: University of Chicago Press.

Comrie, B. 1989. Language Universals and Linguistic Typology. 2nd edition. Chicago, IL: University of Chicago Press.

Croft, W. 1991. Syntactic Categories and Grammatical Relations. The Cognitive Organization of Information. Chicago, IL: University of Chicago Press.

Croft, W. 2003. Typology and Universals. Cambridge: CUP.

Derbyshire, D. \& G. Pullum. 1981. Object-initial Languages. International Journal of American Linguistics 47.3, 192-214.

Derbyshire, D. \& G. Pullum (eds.) 1986. Handbook of Amazonian Languages I. Berlin: Mouton de Gruyter.

Dryer, M. 1991. SVO Languages and the OV: VO Typology. Journal of Linguistics 27, 443-482.

Dryer, M. 1992. The Greenbergian Word Order Correlations. Language $68,81-138$.

Dryer, M. 1997. On the Six-way Order Typology. Studies in Language 2.1, 69-103.

Fedzechkina, M. et al. 2017. Balancing Effort and Information Transmission during Language Acquisition: Evidence from Word Order and Case Marking. Cognitive Science 41.2, 416-446 (http://doi.10.1111/cogs.12346). 
Givón, T. 1997. Grammatical Relations: An introduction. In T. Givón (ed.), Grammatical Relations: A Functional Perspective 1-84. Amsterdam: John Benjamins.

Givón, T. 2001. Syntax I. Amsterdam: John Benjamins.

Goddard, I. 1967. Remarks on the Algonquian Independent Indicative. National Museum of Canada Bulletin 214, 66-106.

Greenberg, J. (ed.) 1963. Universals of Language. Cambridge, MA: MIT Press.

Greenberg, J. 1966a. Some Universals of Grammar with Particular Reference to the Order of Meaningful Elements. In J. Greenberg (ed.), Universals of Grammar 73-113. Cambridge, MA: MIT Press.

Greenberg, J. 1966b. Synchronic and Diachronic Universals in Phonology. Language 42, 508-517.

Hahn, M. et al. 2020. Universals of Word Order Reflect Optimization of Grammars for Efficient Communication. Proceedings of the National Academy of Sciences 117.5, 2347-2353.

Haider, H. 1988. 0-Tracking Systems-Evidence from German. In L. Maräcz \& P. Muysken (eds.), Configurationality 185-206. Dordrecht: Foris.

Haspelmath, M. 2000. Optimality and Diachronic Adaptation. Zeitschrift für Sprachwissenschaft 18, 180-205.

Haspelmath, M \& S. Michaelis. 2017. Analytic and Synthetic. Language Variation-Eurpean Perspectives VI: Selected Papers from the 8th International Conference on Language Variation in Europe (ICLaVE8). Amsterdam: John Benjamins.

Hawkins, J. 1983. Word Order Universals. New York: Academic Press.

Keenan, E. 1978. The Subject of Subject-final Languages. In W. Lehmann (ed.), Syntactic Typology: Studies in the Phenomenology 
170 Is Unish Moving toward Becoming a More Analytic Language?

of Language 267-327. Austin, TX: University of Texas Press. Keenan, E. \& M. Dryer. 2007. Passives in the World's Languages. In

T. Shopen (ed.), Language Typology and Syntactic Description 325-361. Cambridge: CUP.

Krifka, M. 1985. Harmony or Consistency? Theoretical Linguistics 12.1, 73-96.

Kroch, A. \& A. Taylor. 2000. Penn-Helsinki Parsed Corpus of Middle English. 2nd edition. Available at <https://www.ling.upenn.edu/ hist-corpora/PPCME2-RELEASE-4/index.html>.

Lee, D. 2002. A Comparison of Unish Grammar with Esperanto. Journal of Universal Language 3.2, 57-74 (http://doi.org/ 10.22425/jul.2002.3.2.57).

Lehmann, W. 1973. A Structural Principle of Language and its Implications. Language 49, 42-66.

Lehmann, W. 1978. The Great Underlying Ground-Plans. In W. Lehmann (ed.), Syntactic Typology 3-55. Austin, TX: University of Texas Press.

Libert, A. 2003. Mixed Artificial Languages. Munich: Lincom Europa.

Libert, A. 2011. International Auxiliary Languages in Korea: Reception and Creation. Paper Presented at the 7th Korean Studies Association of Australasia (KSAA) Biennial Conference, University of New South Wales, Sydney.

Libert, A. 2012. The Representation of Korean and Other Altaic Languages in Artificial International Auxiliary Languages. Journal of Universal Language 13.1, 125-167 (http://doi.org/ 10.22425/jul.2012.13.1.125).

Libert, A. 2018. Artificial Languages. Oxford: OUP.

Libert, A. \& C. Moskovsky. 2011. Aspects of the Grammar and Lexica of Artificial Languages. Frankfurt: Peter Lang. 
Lightfoot, D. 2002. Introduction. In D. Lightfoot (ed.), Syntactic Effects of Morphological Change 1-22. Oxford: OUP.

Lupyan, G. et al. 2010. Language Structure is Partly Determined by Social Structure. PLOS ONE 5.1, e8559.

Mithun, M. 1987. Is Basic Word Order Universal? In T. Russell (ed.), Coherence and Grounding in Discourse 281-328. Amsterdam: John Benjamins.

Moskovsky, C. \& A. Libert. 2004. Possibilities for Passives in Natural and Artificial Languages. Journal of Universal Language 5.2, 101-149 (https://doi.org/1022425/jul.2004.5.2.101).

Müller, G. 1999a. Optimality, Markedness, and Word Order in German. Linguistics 37.5, 777-818.

Müller, G. 1999b. Optionality in Optimality-Theoretic Syntax. GLOT International 4.5, 3-8.

Okrent, A. 2014. Artificial Language. Oxford: OUP.

Payne, D. (ed.) 1990. Amazonian Linguistics: Studies in Lowland South American Languages. Austin, TX: University of Texas Press.

Sejong Language Institute. 2012. Unish Grammar. Seoul: Sejong University Press.

Sejong Language Institute. 2020. Unish Grammar. Seoul: Sejong University Press.

Thompson, L. \& T. Thompson. 1969. Metathesis as a Grammatical Device. International Journal of American Linguistics 35, 213 219.

Tomlin, R. 1986. Basic Word Order: Functional Principles. London: Croom Helm.

Vennemann, T. 1974. Theoretical Word Order Studies: Results and Problems. Papiere zur Linguistik 7, 5-25.

Vennemann, T. 1976. Categorial Grammar and the Order of Meaningful 
172 Is Unish Moving toward Becoming a More Analytic Language?

Elements. In A. Juilland (ed.), Linguistic Studies Offered to Joseph Greenberg on the Occasion of his Sixtieth Birthday 615634. Saratoga, CA: Anma Libri. 